\title{
Carried away by a moonlight shadow: activity of wild boar in relation to nocturnal light intensity
}

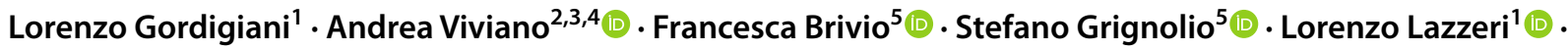 \\ Andrea Marcon ${ }^{6}$ (1) $\cdot$ Emiliano Mori ${ }^{4} \mathbb{0}$
}

Received: 12 July 2021 / Accepted: 16 November 2021 / Published online: 4 December 2021

(c) The Author(s) 2021

\begin{abstract}
An increase of nocturnal activity of ungulate species may represent a compensatory opportunity for energy intake, when activity in daylight is hindered by some disturbance events (e.g. hunting or predation). Therefore, mostly-diurnal and crepuscular species may be active in bright moonlight nights whereas others may shift their diurnal activity towards darkest nights to limit their exposure to predators. In natural and undisturbed conditions, the wild boar may be active both during the day and the night, with alternating periods of activity and resting. In this work, we tested whether activity patterns of wild boar, a species with poor visive abilities, were dependent on moon phases and environmental lightening. We aimed to assess if nocturnal activity could be better explained by variations of the lunar cycle or by the variations of environmental lightening conditions, evaluated by means of different measures of night brightness. Data were collected through camera-trapping in Central Italy in 2019-2020. Despite the poor visive abilities of the wild boar, we observed that this ungulate significantly reduced their activity by avoiding the brightest nights. In our study area, the wild boar has to cope with both human pressure (i.e. mostly hunters and poachers) and predation by the grey wolf. Furthermore, the nocturnal activity of wild boar peaked in mid-Autumn, i.e. when hunting pressure is the highest and when leaf fall may bring wild boar to range for long distances to find suitable resting sites for diurnal hours.
\end{abstract}

Keywords Activity rhythms · Closed habitats · Open habitats $\cdot$ Moonlight $\cdot$ Sus scrofa $\cdot$ Ungulates

\section{Introduction}

Predation avoidance is a pivotal factor shaping the nocturnal activity of wildlife, which has been modeled by evolution to local environmental variables (Lima and Dill 1990; Ferrari et al. 2009; Monterroso et al. 2013). In this context, prey species developed strategies to avoid predation

Emiliano Mori

emiliano.mori@cnr.it

Lorenzo Gordigiani

gordazzoni@gmail.com

Andrea Viviano

a.viviano@studenti.unipi.it

Lorenzo Lazzeri

lazzerilorenzo12@gmail.com

1 Dipartimento di Scienze della Vita, Università di Siena, Via P.A. Mattioli 4, 53100 Siena, Italy

2 CREA Research Centre for Plant Protection and Certification, Via di Lanciola 12/a, Cascine del Riccio, 50125 Firenze, Italy by developing survival tactics, whereas predators have to learn how to overcome those tactics in a sort of arms race (Monterroso et al. 2013). Although adapted to find prey in darkness, most nocturnal carnivores improve their hunting success on the brightest nights, i.e. in full moon and clear sky (Lima Sábato et al. 2006; Harmsen et al. 2011; Cozzi et al. 2012; Bhatt et al. 2021). In turn, prey species often

3 Dipartimento di Scienze Agrarie, Alimentari e Agro-ambientali, Produzioni Agroalimentari e Gestione degli Agroecosistemi, Università degli Studi di Pisa, Via del Borghetto 80, 56124 Pisa, Italy

4 Consiglio Nazionale delle Ricerche, Istituto di Ricerca sugli Ecosistemi Terrestri, Via Madonna del Piano 10, 50019 Sesto Fiorentino, Florence, Italy

5 Dipartimento di Medicina Veterinaria, Università di Sassari, Via Vienna 2, 07100 Sassari, Italy

6 ISPRA, Via Ca'Fornacetta 9, 40064 Ozzano nell'Emilia, Bologna, Italy 
decrease predator efficiency by moving in darkest nights, i.e. in new moon (Daly et al. 1992; Penteriani et al. 2013; Mori et al. 2014) and/or in densely wooded/scrubland habitats (Fattorini and Pokheral 2012; Prugh and Golden 2014). In other cases, when diurnal species are brought to develop nocturnal habits to limit encounters with humans or when visual acuity is low, preys may also be mostly active in bright moonlight to increase their ability to detect predators (e.g. Brown et al. 2011; Carnevali et al. 2016; Grignolio et al. 2018). Moonlight avoidance has been mostly recorded in small prey species, including rodents, marsupials and lagomorphs (Sutherland and Predavec 1999; Griffin et al. 2005; Mori et al. 2014; Viviano et al. 2021). Conversely, this behaviour has been poorly assessed in ungulates (Medici 2010; Brown et al. 2011; Jasińska et al. 2021; Table 1).

Nocturnal behaviour of ungulates is often reported as a compensatory opportunity for energy intake when activity in daylight is hindered by hunting or predation risk (Carnevali et al. 2016; Visscher et al. 2017; Grignolio et al. 2018). Therefore, in some cases (e.g. in the lowland tapir Tapirus terrestris and in the white-tailed deer Odocoileus virginianus), also ungulates may increase their activity in brightest nights, when their ability to detect predators is the highest (Medici 2010; Brown et al. 2011). Lashley et al. (2014) confirmed that, when nocturnal visibility increases, ungulates may increase their feeding activity by reducing vigilance time, as predators can be better detected in full moon nights than in dark nights. However, all these studies only tested for the effects of moon phases on ungulate activity. In other words, this kind of analysis only tells whether a lunar synodic endogenous clock is present in animal species (Youthed and Moran 1969; Kronfeld-Schor et al. 2013), but it does not provide an actual estimation of the effect of environmental lightening on their nocturnal activity. Studies on activity rhythms of nocturnal small-sized mammals and other species report that some of them tend to reduce their detectability by limiting their activity on the brightest nights, which includes both bright full moon and clear skies (Elangovan and Marimuthu 2001; Jetz et al. 2003; Cozzi et al. 2012).

The wild boar Sus scrofa is the most widespread wild ungulate in the world (Barrios-Garcia and Ballari 2012). This species is native to Eurasia and it has been introduced, often with hybrid individuals with domestic pigs Sus scrofa domestica, to most of America, Africa and several oceanic islands (Barrios-Garcia and Ballari 2012). The wild boar generates one of the most important conflicts with human activities and wellness, mostly as being a crop pest (Massei et al. 1997; Apollonio et al. 2010; Ficetola et al. 2014;

Table 1 Summary of studies assessing the effect of moon phase on the activity of ungulate species

\begin{tabular}{|c|c|c|c|c|}
\hline & Species & Study area & Effect of moon phase & Reference \\
\hline \multirow[t]{5}{*}{ Bovidae } & Eudorcas thomsoni & Tanzania (open habitats) & Activity peak in brightest nights & Walther (1973) \\
\hline & Oryx gazella & South Africa (open habitats) & Activity peak in brightest nights & Joubert and Eloff (1971) \\
\hline & Tragelaphus scriptus & Uganda (open habitats) & No effect & Wronski et al. (2006) \\
\hline & Tragelaphus strepsiceros & South Africa (open habitats) & Activity peak in brightest nights & Joubert and Eloff (1971) \\
\hline & Rupicapra rupicapra & Italy (Italian Alps) & Activity peak in brightest nights & $\begin{array}{l}\text { Carnevali et al. (2016); } \\
\text { Grignolio et al. (2018) }\end{array}$ \\
\hline \multirow[t]{10}{*}{ Cervidae } & Capreolus capreolus & Italy (woodland) & No effect & Pagon et al. (2013) \\
\hline & & Italy (rural area) & No effect & Viviano et al. (2021) \\
\hline & & Poland (suburban forests) & Activity peak in darkest nights & Jasińska et al. (2021) \\
\hline & Capreolus pygargus & Mongolia (steppe and mountain) & No effect & Mori et al. (2021a) \\
\hline & Cervus canadensis & Oregon, USA (open habitats) & No effect & Woodside (2010) \\
\hline & & Alberta, Canada (open habitats) & Activity peak in brightest nights & Visscher et al. (2017) \\
\hline & Odocoileus virginianus & Pennsylvania, USA (open areas) & Activity peak in brightest nights & Brown et al. (2011) \\
\hline & & Pennsylvania, USA (woodland) & Activity peak in darkest nights & Brown et al. (2011) \\
\hline & & USA (open habitats) & Activity peak in brightest nights & Kie (1999) \\
\hline & & USA (mix forests/open areas) & No effect & Webb et al. (2010) \\
\hline \multirow[t]{5}{*}{ Tapiridae } & Tapirus terrestris & Brazil (scrubland) & No effect & Oliveira-Santos et al. (2010) \\
\hline & & Brazil (forest) & Activity peak in brightest nights & Medici (2010) \\
\hline & & Ecuador (forest) & No effect & Link et al. (2012) \\
\hline & Tapirus terrestris & Argentina (forest) & No effect & Cruz et al. (2014) \\
\hline & Tapirus pinchaque & Colombia (mountain forests) & Activity peak in brightest nights & Lizcano and Cavelier (2000) \\
\hline \multirow[t]{3}{*}{ Suidae } & Phacochoerus aethiopicus & South Africa (open habitats) & Activity peak in brightest nights & Shortridge (1934) \\
\hline & Sus scrofa & Central Italy (woodland) & Activity peak in brightest nights & Brivio et al. (2017) \\
\hline & & Germany (open habitats) & No effect & Johann et al. (2020) \\
\hline
\end{tabular}


Laurenzi et al. 2016). Wild boar activity lasts typically 6-12 h a day (Boitani et al. 2003; Lemel et al. 2003). Seasonal variation in activity patterns is usually scarce (Keuling et al. 2013; Mori et al. 2020), although some daily adjustments may occur as a response to changes in temperature, photoperiod, precipitation and humidity (Brivio et al. 2017). In natural and rural conditions, wild boar usually alternates periods of activity and resting both during daylight and night hours (Podgórski et al. 2013; Brivio et al. 2017; Mori et al. 2020; Rossa et al. 2021; Zanni et al. 2021). Conversely, in human-dominated landscapes, wild boar is mostly nocturnal to reduce interference with humans, independently of the seasonal changes in photoperiod (Keuling et al. 2013; Brivio et al. 2017). As other primarily diurnal species (Carnevali et al. 2016; Grignolio et al. 2018), the nocturnal activity of the wild boar mostly occurs on bright moonlight nights, when environmental lighting should be the highest, particularly where natural predators occur (Brivio et al. 2017).

On the brightest nights, the number of collisions between wild boar and vehicles also increases, as a result of the increased movements of ungulates in areas of highest visibility, e.g. paved road (Colino-Rabanal et al. 2018). Conversely, Johann et al. (2020) detected no effect of moon phase on activity patterns in rural areas where natural predators are absent. Theuerkauf et al. (2003) reported that hunting success of wolves (Canis lupus) is the highest in bright full moon night. Although it may be surprising to detect the highest activity of a prey species overlapping with that of its main predator (cf., Brivio et al. 2017), the poor visual acuity of the wild boar may imply that ranging movements would be mostly concentrated when environmental visibility is good enough. Thus, being active in bright nights may represent a profitable trade-off for wild boar, which may reduce their visibility to some predators and hunters and may, at the same time, detect potential others. Conversely, Rossa et al. (2021) showed that in the Mediterranean scrubland, i.e. a concealed habitat, the activity of wild boar was not influenced by that of wolf.

Given the seasonality of hunting periods, the activity of wild boar may seasonally change not only following the seasonal differences in night and day duration, but also in light of different risk perception (Boitani et al. 2003). Accordingly, when nights are shorter (e.g. at the start of the spring), wild boar may compensate by being active also in some diurnal hours (cf. Brivio et al. 2017). As well, particularly during the hunting period (i.e. in late autumn-early winter), wild boar may avoid humans by being more active in nighttime. In this study, we compared the performance of some competitive models using different variables describing the moon cycle or estimating the actual nocturnal brightness on the ground, to find which one better explain the activity probability (AP) of wild boar during night. In this way, we investigated whether a lunar synodic endogenous clock is the most powerful driver in determining wild boar activity patterns or if the actual brightness of the night is a more important factor affecting their activity. We took also into account the potential effect of Julian night (i.e. a proxy of seasonality) in determining nocturnal activity. Given the local hunting pressure, we predicted that wild boar would increase their nocturnality in autumn and winter to limit encounters with humans. However, some nocturnal behaviour could be maintained throughout the year to limit visibility to predators (i.e. wolves) and potential poachers. We also predicted that wild boar would reduce their detectability by reducing activity in the brightest nights throughout the year.

\section{Study area and sampling design}

Our survey was carried out in the North-Eastern part of the province of Grosseto, Central Italy ("Poggi di Prata", about 1400 ha, $43.08^{\circ} \mathrm{N} 10.99^{\circ} \mathrm{E} ; 1350$ ha; $475-903 \mathrm{~m}$ a.s.l.: Battocchio et al. 2017; Viviano et al. 2021), throughout 2019 and 2020. About $67 \%$ of the study site was covered by deciduous mixed oakwoods (mostly Quercus cerris L., Castanea sativa Miller, Ostrya carpinifolia Scop., Carpinus betulus L., Fraxinus ornus L. and Robinia pseudoacacia L.). A belt of scrubland (Juniperus communis L., Rubus ulmifolius Schott. and Spartium junceum L.: 1.7\%) occurred around woodlands. Fallows count for $19.5 \%$, cultivations (sunflowers, cereals and vegetable gardens) for $7.8 \%$. Coniferous woodlands (Pinus nigra Arnold and Cupressus arizonica Greene) and human settlements covered the remaining part of the study area. A map of the study area could be seen in Fig. 1 (cf. Mori et al. 2021b; Viviano et al. 2021). Three brooks and some ponds fed by rainfall are present. The local climate shows sub-montane features: during our survey, the average annual rainfall was $850 \mathrm{~mm}$ and the average annual temperature was $15^{\circ} \mathrm{C}$. Drive-hunt to wild boar is conducted throughout the study area, between the 1 st of November and the 31 st of January. Some poaching is known to occur in the surroundings of farmlands and other cultivated areas (e.g. vegetable gardens). The grey wolf was present in the study area and the wild boar represented the main prey species in the study area ( $44 \%$ of relative frequency over a total of 117 wolf scats: Battocchio et al. 2017).

Camera traps $(\mathrm{N}$ tot $=7)$ were placed at 25 stations (Fig. 1) across all habitat types of the study area, in proportion to their local availability. Stations were separated oneanother by at least $500 \mathrm{~m}$ (Battocchio et al. 2017; Greco et al. 2021). Although home range size of the wild boar in Central Italy can be larger in size (Boitani et al. 1994; Massei et al. 1997), presence of fences around open areas as well as short duration of each camera-trap deployment (14 nights) may have limited the occurrence of the same wild boar groups at different stations during the same deployment (cf. Greco et al. 2021). Cameras were distributed in all habitat types, 

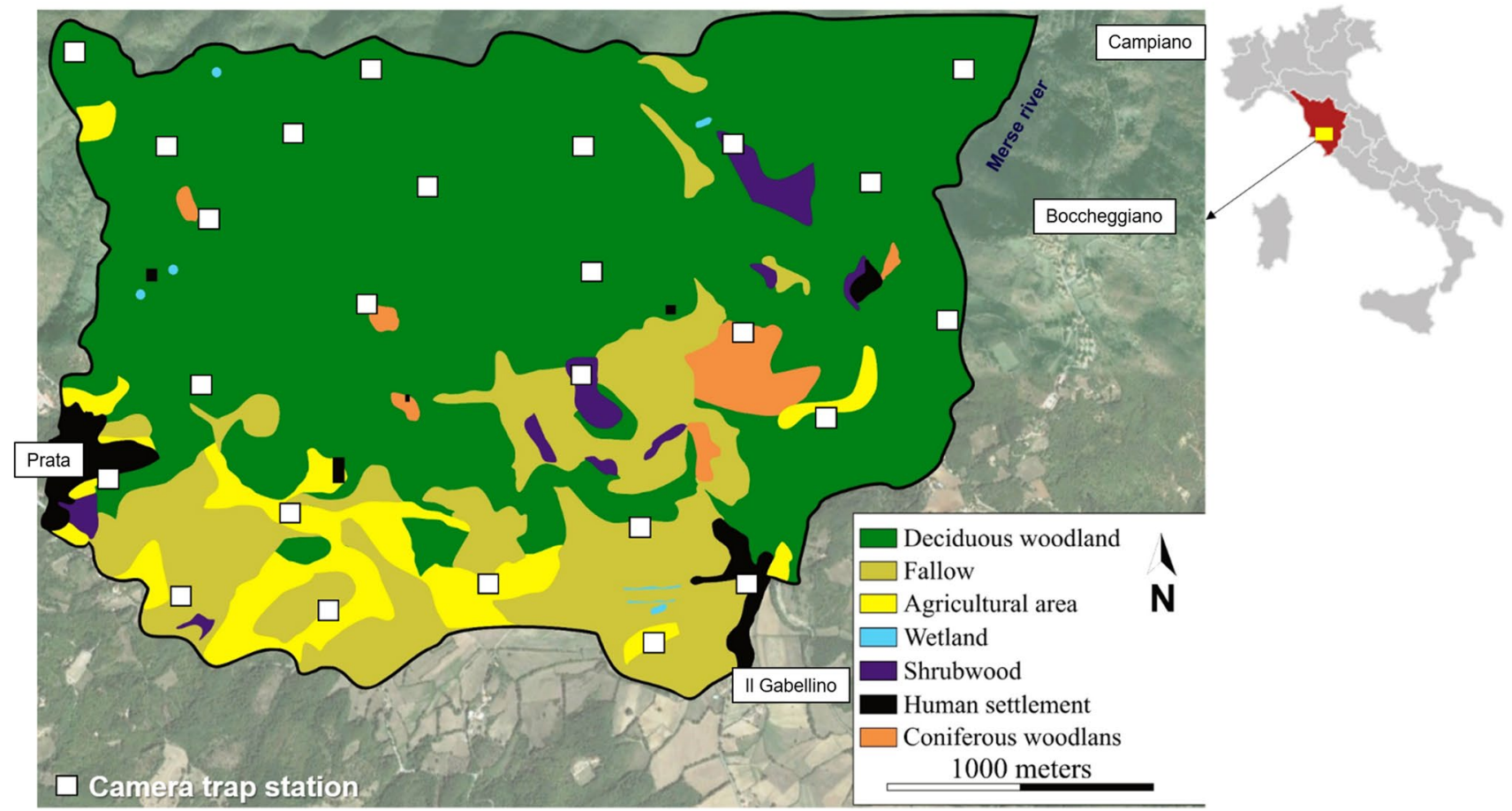

Fig. 1 Map of the study area, with camera trap stations and main habitat types

including forest patches and areas over the tree-line level, depending on their accessibility. Camera traps were placed at an average height of $80 \mathrm{~cm}$ from ground level (Mori et al. 2020; Greco et al. 2021) on random points. We used Multipir 12 cameras, triggered by Passive InfraRed sensor (PIR). The cameras were furnished with eight $1.5 \mathrm{~V}$ alkaline batteries and 16 GB SD cards. The cameras were set to record videos of $60 \mathrm{~s}$ with a minimum time interval between one video and the next of about $5 \mathrm{~s}$. Camera trigger time was about $1.2 \mathrm{~s}$. The camera traps had a detection range of up to $20 \mathrm{~m}$ $\left(15 \mathrm{~m}\right.$ at night) and a horizontal field of view of $90^{\circ}$. Camera traps were activated for $24 \mathrm{~h}$ a day and checked once every 14 days to download data and replace dead batteries. Camera traps were randomly rotated between stations once every 14 nights, so that each station was sampled for 45-62 days per season (Table S1 in Supplementary Material 1). No camera failure occurred during our survey.

\section{Pattern of activity rhythms}

For each detection of wild boar, we reported on a dataset the date and the solar time of capture, which is directly shown on each camera trap record. Hours were converted into radians before the statistical analysis on the package overlap (Meredith and Ridout 2014) for the software R 3.6.1 (R Core Team 2013). Records occurring at the same cameratrap location within less than $30 \mathrm{~min}$ were removed from the dataset by keeping only one intermediate hour between the first and the last detection, to limit pseudo-replication (Meredith and Ridout 2014). So, all the detections included in the final dataset were considered "independent." Records were classified following astronomical seasons: spring (21st March-20th June), summer (21st June-20th September), autumn (21st September-20th December) and winter (21st December-20th March). Seasonal patterns of activity rhythms and associated 95\% confidence intervals (hereafter, CIs) were calculated with the package overlap. Dawn and dusk times were calculated through the R package NightDay (Hughes-Brandl 2018). We estimated all the coefficients of temporal overlapping $(\Delta)$ between all pairwise combinations of the four seasons. The coefficient of overlapping ranges between 0 (no overlap) and 1 (total overlap: Meredith and Ridout 2014). We calculated the $\Delta_{4}$ estimator and its $95 \%$ confidence intervals (hereafter, CIs) as also the smallest sample of the pairwise comparison was over 75 records (Meredith and Ridout 2014).

Seasonal Hermans-Rasson tests were computed through the R package circMLE (Fitak 2020), to evaluate whether a random activity pattern was exhibited over the $24 \mathrm{~h}$ (Landler et al. 2019). This test evaluates if activity data collected through camera-trapping are drawn from a uniform distribution or they are concentrated around one or more preferred directions (i.e. hours of the day). The Mardia-Watson-Wheeler test (W) was computed to estimate interseasonal overlaps of activity rhythms. Bootstrap tests were used to obtain a probability test that two sets of 
circular observations (i.e. from two seasons) belonged to the same distribution, for all season pairs, with the function compareCkern() of the R-package activity (Rowcliffe et al. 2008, 2014).

\section{Nocturnal activity}

To assess the effect of night brightness on wild boar activity patterns, we estimated the probability to detect active wild boar during the night depending on different measures of night brightness. To this aim, we prepared a new dataset in which the sampling period of each camera trap (i.e. the actual days when the camera trap was active) was split into two-hour intervals. For each two-hour interval, we defined a new variable named "activity probability" (hereafter, AP), which assumes value 1 , when at least one wild boar was detected by the camera trap during the corresponding two hours, and 0 , when no wild boar was detected (ratio of 0 to $1=0.97)$. Then, we focused on nocturnal records only: all two-hour intervals were classified as nocturnal if at least $50 \%$ of interval time was before dawn or after dusk.

We considered different measures of night brightness which consider natural (i.e. lunar) and anthropogenic light sources, as well as cloud cover of the sky which may have affected the illumination level of the moon. Thus, we computed through a visual assessment every night at midnight in an open area: (1) moon phase (phase 1 , from new moon to $1 / 4$; phase 2 , from $1 / 4$ to $1 / 2$; phase 3 , from $1 / 2$ to $3 / 4$ and phase 4, over $3 / 4$ ), (2) lunar age (i.e. 0-29 days of epact), (3) moon visibility (i.e. veiled, covered, or fully visible), (4) lightening (at ground level and at every camera trap station, including anthropogenic light sources, computed by the $\odot$ KHTSXR Luxmeter App for Android smartphones: Zozzoli et al. 2018), (5) cloud cover (in percentage with a 10\% accuracy), and (6) a sky brightness index, i.e. an indicator resulting from the joint effects of moon phase and sky cloudiness preventing moon visibility (Luzi et al. 2021). To calculate it, we multiplied the moon phase per moon visibility $(0.1$, when moon was completely or almost hidden by clouds;
0.5 , when moon was partially veiled by clouds; 1 , when sky was clear and moon fully visible) to obtain this index, ranging from 0.1 (maximum sky darkness) to 4 (maximum sky brightness).

To analyse the influence of night brightness on wild boar activity, we modelled AP by using Generalized Additive Models (GAMs) with binomial distribution. GAMs were implemented within the $m g c v$ package in R (Wood 2017). As the six different measure of night brightness were highly correlated (see Supplementary materials S1), we fitted six alternative GAMs one for each measure of night brightness (moon phase, lunar age, moon visibility, sky cover, lightening, and sky brightness index) to evaluate which one better explain the activity probability of wild boar during night (Table 2). In each GAM, we included the sampling time (two-hour interval) and the date (Julian night), to account for daily and seasonal variations in wild boar activity rhythms. The effect of the date was modelled as a cyclic cubic regression spline, to take into account the circularity of this variable: thus, we ensured that the value of the smoother at the far-left point (1 January) was the same as the one at the far-right point (31 December). Camera station ID and year of data collection were fitted as random factors to control for the influence of camera-related factors (e.g. vegetation cover, distance to water) and year-related environmental conditions (e.g., weather, food availability), by declaring them in the GAMs formulas using "re" terms and smoother linkage (Wood 2013). Predictors were screened for collinearity (Pearson correlation matrix) and multicollinearity (Variance Inflation Factor), with thresholds set to $\mid r p l=0.5$ and VIF $=3$, respectively. Wild boar sex was not included in our model, as it was possible to recognise amongst males and females only in few records. We ranked and weighed the six alternative GAMs by using the minimum AIC criterion (Symonds and Moussalli 2011), to find which model was best supported by the empirical data, thus identifying the measure of night brightness, which best explain wild boar activity pattern variations.
Table 2 Alternative Generalised Additive Models predicting the nocturnal activity of the wild boar in Central Italy

\begin{tabular}{lllrr}
\hline Model \# & Variables in the model & AIC & $\Delta$ AIC & Log Lik \\
\hline Model 6 & activity $\sim$ j. night + time-int. + sky brightness index & 8834.1 & 0.0 & -4384.2 \\
Model 4 & activity $\sim$ j. night + time-int. + lightening & 8869.3 & 35.2 & -4401.2 \\
Model 5 & activity $\sim$ j. night + time-int. + sky cover & 8890.2 & 56.1 & -4411.9 \\
Model 3 & activity $\sim$ j. night + time-int. + moon visibility & 8908.2 & 74.0 & -4426.1 \\
Model 2 & activity $\sim$ j. night + time-int. + lunar age & 8922.6 & 88.5 & -4434.8 \\
Model 1 & activity $\sim$ j. night + time-int. + moon phase & 8927.1 & 93.0 & -4434.8 \\
Null model & activity $\sim$ 1 & 9088.0 & 253.8 & -4543.0 \\
\hline
\end{tabular}




\section{Results}

Analyses on activity rhythms were carried out on a total of 1048 independent records (first year, 507; second year, 541). Throughout the year, wild boars were mostly nocturnal, particularly in the warmest months, with a peak around midnight (Fig. 2). Annual and seasonal activity patterns were significantly different from random according to the Hermans-Rasson test $(r=70.16-81.34$, all $P<0.001)$ and activity peaked in the first part of the night (i.e. after sunset) in all seasons. However, interseasonal temporal overlaps were very high and patterns of temporal overlap were similar across seasons $\left(\Delta_{4}=0.78-0.94\right.$,
95\% CIs $=0.75-0.97$, all bootstrap $P>0.05$ ). We observed a very high temporal overlap between sampling years $\left(\Delta_{4}=0.96,95 \%\right.$ CIs $\left.=0.91-0.98\right)$. We did not detect any significant difference in the comparison of temporal overlaps of each season pair (Mardia-Watson-Wheeler tests, $\mathrm{W}=0.052-0.085$, all $P>0.10)$.

\section{Nocturnal activity}

According to the minimum AIC criterion, the best model explaining wild boar activity during night includes the sky brightness index (Tables 2 and 3). Results of the model showed that throughout the year, nocturnal activity peaked
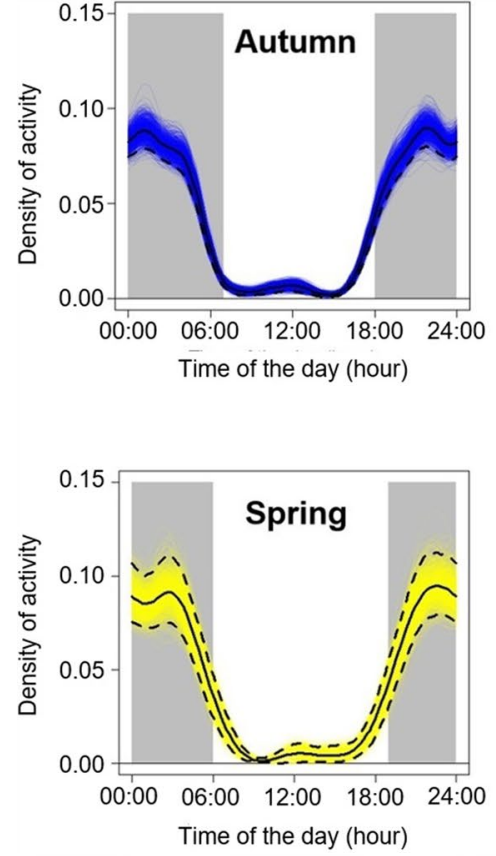

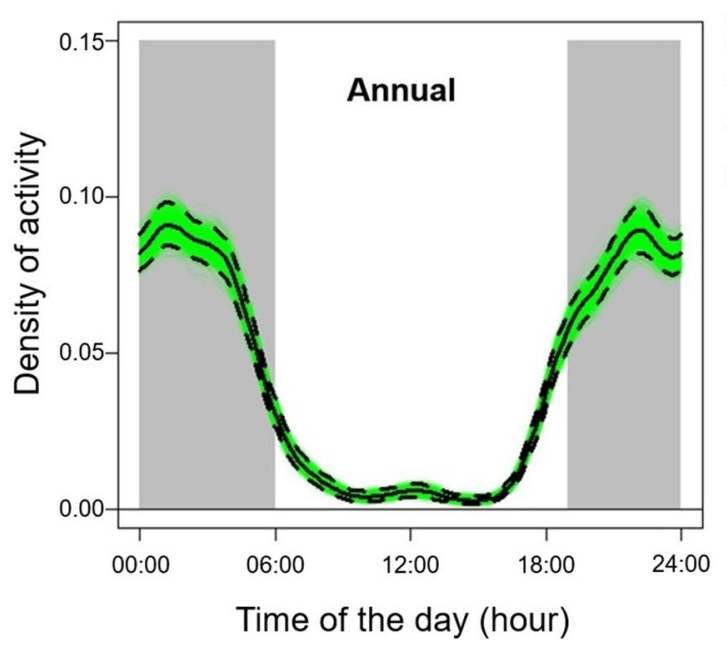

Fig. 2 Patterns of activity rhythms of the wild boar in Central Italy assessed through kernel density estimate of activity throughout the year (annual, $N=1048$ camera-trap records), and in each season (autumn, $N=255$; winter, $N=272$; spring, $N=291$; summer,
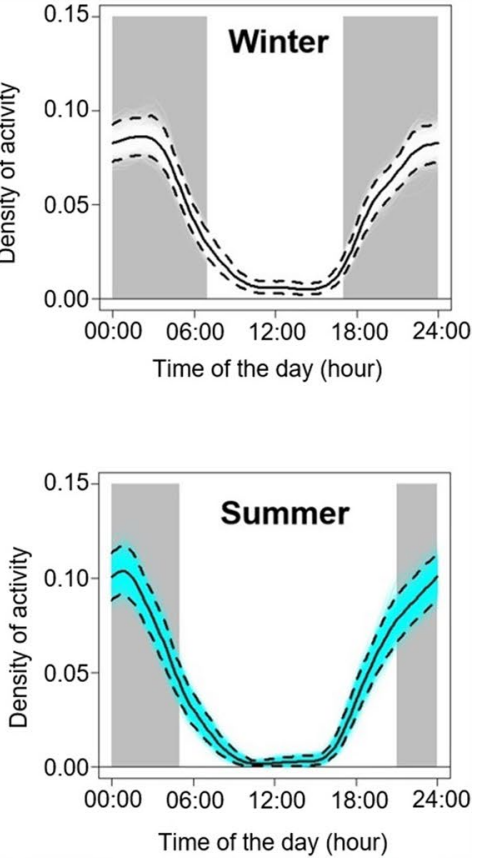

$N=230$ ). Coloured lines represent bootstrap estimates. In each graph, the black line is the mean activity pattern and dashed lines represent 95\% confidence intervals
Table 3 Effect of predictor variables estimated by the best Generalised Additive Model (see the text for more details) fitted to predict the nocturnal activity of the wild boar in Central Italy

\begin{tabular}{|c|c|c|c|c|c|c|c|}
\hline \multicolumn{8}{|l|}{ Parametric coefficients: } \\
\hline & & Estimate & Std. error & $\mathrm{z}$ value & & $\operatorname{Pr}(>|z|)$ & \\
\hline (Intercept) & & -3.361 & 0.124 & -27.08 & & $<0.001$ & $* * *$ \\
\hline \multicolumn{8}{|c|}{ Approximate significance of smooth terms: } \\
\hline & edf & & Ref.df & Chi.sq & $p$-value & & \\
\hline s (Julian night) & 1.785 & & 2 & 22.382 & $<0.001$ & & $* * *$ \\
\hline s (time interval) & 3.883 & & 4 & 77.809 & $<0.001$ & & $* * *$ \\
\hline s (sky brightness index) & 2.967 & & 3 & 33.969 & $<0.001$ & & $* * *$ \\
\hline s (site) & 17.727 & & 24 & 74.157 & $<0.001$ & & $* * *$ \\
\hline s (year) & 0.896 & & 1 & 9.115 & 0.001 & & $* *$ \\
\hline
\end{tabular}




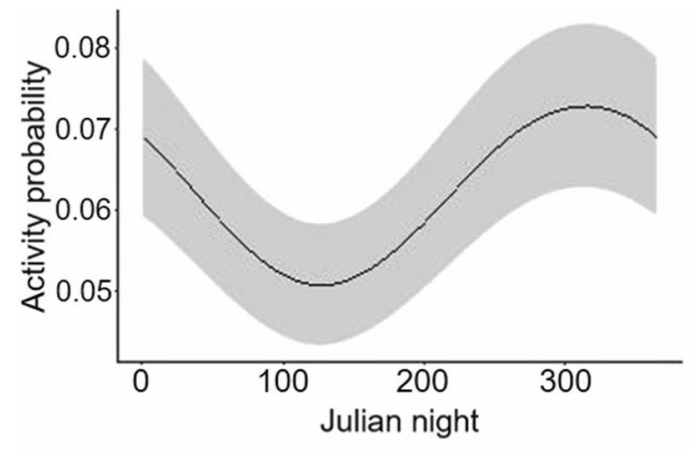

A)

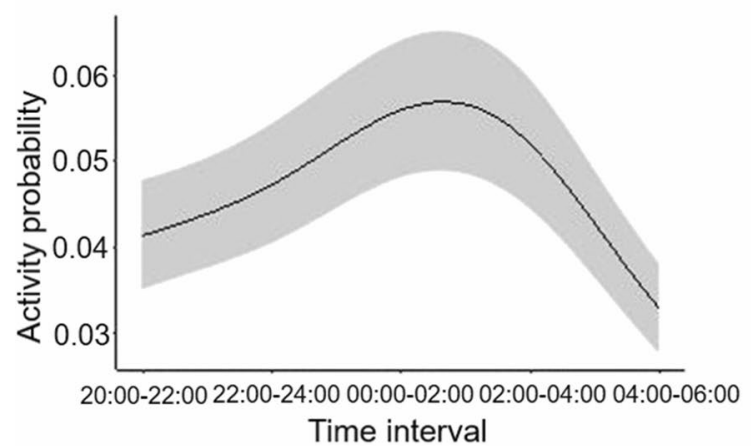

B)

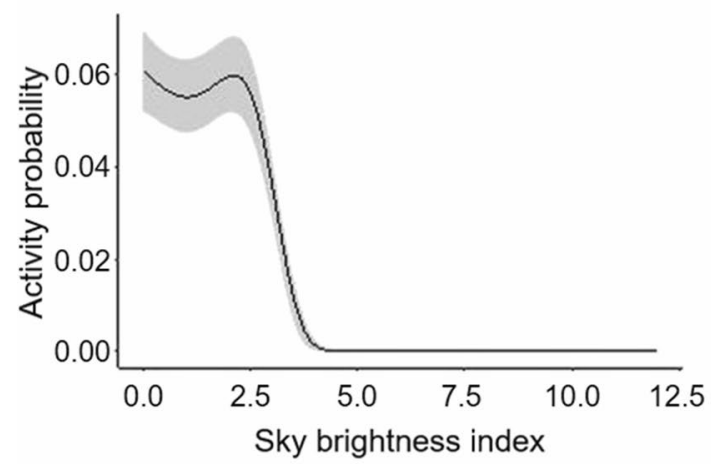

Fig. 3 Predicted wild boar nocturnal activity in Central Italy following the best Generalised Additive Model. The figure shows the effects exerted by Julian night (A), time (B), and the sky brightness index (C). The predictions are given according to the mean of all other covariates in the model. In the graphs, the gray-shaded areas are the estimated standard errors

around 3rd November (i.e. 307th Julian night, Fig. 3A), while minimum values were recorded around 3rd May (i.e., 123rd Julian night, Fig. 3A). Activity peaked around midnight, after which decreased towards dawn. Interestingly, activity around dusk was higher than that around dawn (Fig. 3B). The maximum nocturnal activity was reported in conditions of low sky brightness index values (range $0-2.5$ ). For nights with a sky brightness index above 2.5 , the activity of wild boar deeply decreased till becoming null for sky brightness index around 4 (Fig. 3C).

\section{Discussion}

Wild boar resulted in being mostly nocturnal, with an acrophase of activity concentrated around midnight, in line with previous literature (Caruso et al. 2018; Mori et al. 2020). A few diurnal activity was observed only in spring, when nights are shorter and likely insufficient to fulfil nutritional requirements of wild boar (Corsini et al. 1995, for the crested porcupine Hystrix cristata). Conversely, diurnal hot temperatures of summer may force wild boar to travel at night, requiring the presence of water for mud baths to thermoregulate.

Activity patterns of wild species are shaped by intrinsic (biological clocks and nutritional requirements) and extrinsic factors (photoperiod, moon cycle, and temperature fluctuations: Daan and Aschoff 1982; Refinetti 2016). Our findings provided the first strong evidence that wild boars limit their activity in nights with high light intensity, i.e. those with bright full moon and clear sky. However, our analysis failed to show any clear lunar synodic pattern defined by environmental stimuli known as "Zeitgebers" (Daan and Aschoff 1982; Kronfeld-Schor et al. 2013), as wild boar activity was explained by the variation in sky brightness (i.e. in light intensity) better than by the variation in lunar day (Youthed and Moran 1969). Accordingly, in our study, the wild boar was mostly active in the darkest nights, i.e. when the sky was particularly cloudy or around new moon nights. The limited visual abilities of the wild boar and the lack of the tapetum lucidum suggest that this ungulate has evolved as a mostly diurnal species (Boitani et al. 2003). In line with its perceptive capabilities, previous studies highlighted that wild boar nocturnal movements are mostly concentrated during brightest nights or crepuscular hours, when environmental visibility is the highest (Brivio et al. 2017; Colino-Rabanal et al. 2018). However, wild boar food search is mostly based on the sense of smell (Ollivier et al. 2004; Morelle et al. 2015; Mori et al. 2021b), allowing this species to range also when environmental visibility is at its lowest (Schlageter and Haag-Wackernagel 2012). Finally, as the model including the actual environmental brightness works better than the models describing moon cycle, we can argue that nocturnal activity cycle is only weakly related to moon cycle. Hence, this result seems to suggest that nocturnal activity has not been evolutionary selected, i.e. a lunar synodic endogenous clock - driving nocturnal activity rhythms — is not present in wild boar. Instead, our results revealed that the activity pattern is a plastic behavioural response of this species which can select the best environmental condition night by night. Human activities are known to shape the spatiotemporal behaviour of the wild boar, which, in turn, shows great ecological plasticity (Podgórski et al. 
2013; Fanelli et al. 2021; Zanni et al. 2021). Particularly, hunting pressure is reported to bring wild boars to increase their spatial movements towards protected areas, which provides suitable refuges for the species (Santilli and Varuzza 2013). In areas characterised by human pressure (e.g. hunting), a shift towards more strictly nocturnal habits is observed in wild boars in respect to protected areas, even outside the hunting season, to limit contacts with humans (Boitani et al. 1994; Keuling et al. 2008; Podgórski et al. 2013; Brivio et al. 2017). In some areas, wild boars develop mostly nocturnal habits only when the risk of encounters with humans is the highest (e.g. hunting season, Ohashi et al. 2013; Johann et al. 2020; Zanni et al. 2021), whereas elsewhere, this ungulate is nocturnal throughout the year (Brivio et al. 2017). In other words, a whole-year nocturnal behaviour may have been developed after decades of severe hunting harassment and, moreover, may provide wild boar with an optimal thermal balance, limiting energetic costs (Brivio et al. 2017).

Predation risk is widely reported to affect the temporal activity patterns of prey species (Borowski and Owadowska 2010; Mori et al. 2020). Thus, the intensity of predation risk by wolf may force wild boar to use the areas where vegetation cover limits their detectability, or roam during darkest nights, as shown by our results. Similarly, Mori et al. (2020) showed that the wild boar increases its nocturnality and reduces diurnal activity in areas where a high frequency of wolf passage was recorded. Our findings showing that wild boars are less active during very bright nights, lead us to interpret this behaviour as an anti-predatory strategy, similar to moonlight avoidance in small mammals (Viviano et al. 2020; Hernández et al. 2021). Thus, where hunting occurs, where predation pressure is high, or in suburban and urban areas, the onset of wild boar activity is usually recorded at sunset (Cahill et al. 2003; Mori et al. 2020; Rossa et al. 2021), whereas in protected areas and where predators are rare, it may occur some hours before (Russo et al. 1997; Podgórski et al. 2013; Zanni et al. 2021). Although many studies have observed a sort of seasonality in wild boar activity, we showed a similar pattern of daily activity rhythms throughout the four seasons, possibly related to climatic conditions in our study area, which are characterised by reduced seasonality in respect to Alpine or Mediterranean areas (Russo et al. 1997; Keuling et al. 2008; Johann et al. 2020). In our study, regarding the Julian nights, the peak of wild boar activity occurred in autumn, thus confirming previous findings (Podgórski et al. 2013; Brivio et al. 2017; Johann et al. 2020). Autumn corresponds to the main hunting season, which is reported to trigger wild boar movements, thus increasing the activity time of this species (Brogi et al. 2020; Johann et al. 2020; Fanelli et al. 2021). Furthermore, after leaves fall, wild boar might have to range for long distances to find suitable resting sites for diurnal hours, often far from feeding areas (Johann et al. 2020).

The great ecological plasticity of wild boar has been suggested to have helped this species to expand its populations throughout Europe (Podgórski et al. 2013; Massei et al. 2015; ENETWILD Consortium et al. 2020), including habitats where it was previously not recorded (i.e. suburban areas: Stillfried et al. 2017). Such a great adaptability requires a high number of studies in different geographical areas to depict a clear knowledge picture. Further research on effect of night brightness on wild boar activity should be carried out comparing areas with and without hunting, as well as with and without wolf predation pressure. Given the severe problems triggered by wild boar populations to human activity and wellness, behavioural plasticity of this species should deserve further attention to explain the expansion process and develop effective management projects (Caro 1998).

Supplementary Information The online version contains supplementary material available at https://doi.org/10.1007/s13364-021-00610-6.

Acknowledgements Three anonymous reviewers kindly improved our first draft with their comments. A native English speaker (E. Basset) kindly took the time to review our MS for language polishing.

Author contribution SG, EM and AV conceived the idea; EM, LG and SG collected most data; LL and AV organised the dataset; SG, FB and AM carried out model analyses; FB created the figures; LG, LL, AM and EM wrote the first draft.

Data availability All data are available via the corresponding author.

\section{Declarations}

Conflict of interest The authors declare no competing interests.

Open Access This article is licensed under a Creative Commons Attribution 4.0 International License, which permits use, sharing, adaptation, distribution and reproduction in any medium or format, as long as you give appropriate credit to the original author(s) and the source, provide a link to the Creative Commons licence, and indicate if changes were made. The images or other third party material in this article are included in the article's Creative Commons licence, unless indicated otherwise in a credit line to the material. If material is not included in the article's Creative Commons licence and your intended use is not permitted by statutory regulation or exceeds the permitted use, you will need to obtain permission directly from the copyright holder. To view a copy of this licence, visit http://creativecommons.org/licenses/by/4.0/.

\section{References}

Apollonio M, Andersen R, Putman R (2010) European ungulates and their management in the twenty-first century. Cambridge University Press, Cambridge 
Barrios-Garcia MN, Ballari SA (2012) Impact of wild boar (Sus scrofa) in its introduced and native range: a review. Biol Invasions 14:2283-2300

Battocchio D, Iacolina L, Canu A, Mori E (2017) How much does it cost to look like a pig in a wild boar group? Behav Processes 138:123-126

Bhatt U, Adhikari BS, Habib B, Lyngdoh S (2021) Temporal interactions and moon illumination effect on mammals in a tropical semievergreen forest of Manas National Park, Assam, India. Biotropica 53:831-845

Boitani L, Mattei L, Nonis D, Corsi F (1994) Spatial and activity patterns of wild boars in Tuscany, Italy. J Mammal 75:600-612

Boitani L, Lovari S, Vigna Taglianti A (2003) Fauna d'Italia. Mammalia III. Carnivora-Artiodactyla. Edagricole Calderini Il Sole 24ore, Bologna, Italy

Borowski Z, Owadowska E (2010) Field vole (Microtus agrestis) seasonal spacing behavior: the effect of predation risk by mustelids. Naturwissensch 97:487-493

Brivio F, Grignolio S, Brogi R, Benazzi M, Bertolucci C, Apollonio M (2017) An analysis of intrinsic and extrinsic factors affecting the activity of a nocturnal species: the wild boar. Mammal Biol 84:73-81

Brogi R, Grignolio S, Brivio F, Apollonio M (2020) Protected areas as refuges for pest species? The case of wild boar. Glob Ecol Conserv 22:e00969

Brown B, Bryntesson F, Cooper S, Nyholm B, Robertson D, Bedford A, Hendricks D, Klippenstein L, Potapov E (2011) Moonlight and suburban white-tailed deer movements. Bull New Jersey Ac Sci 56:1-4

Cahill S, Llimona F, Gràcia J (2003) Spacing and nocturnal activity of wild boar Sus scrofa in a Mediterranean metropolitan park. Wildl Biol 9:3-13

Carnevali L, Lovari S, Monaco A, Mori E (2016) Nocturnal activity of a "diurnal" species, the northern chamois, in a predator-free Alpine area. Behav Processes 126:101-107

Caro T (1998) Behavioural ecology and conservation biology. Oxford University Press, Oxford

Caruso N, Valenzuela AE, Burdett CL, Luengos Vidal EM, Birochio D, Casanave EB (2018) Summer habitat use and activity patterns of wild boar Sus scrofa in rangelands of central Argentina. PLoS One 13:e0206513

Colino-Rabanal VJ, Langen TA, Peris SJ, Lizana M (2018) Ungulate: vehicle collision rates are associated with the phase of the moon. Biodivers Conserv 27:681-694

Corsini MT, Lovari S, Sonnino S (1995) Temporal activity patterns of crested porcupines Hystrix cristata. J Zool 236:43-54

Cozzi G, Broekhuis F, McNutt JW, Turnbull LA, Macdonald DW, Schmid B (2012) Fear of the dark or dinner by moonlight? Reduced temporal partitioning among Africa's large carnivores. Ecology 93:2590-2599

Cruz P, Paviolo A, Bó RF, Thompson JJ, Di Bitetti MS (2014) Daily activity patterns and habitat use of the lowland tapir (Tapirus terrestris) in the Atlantic Forest. Mammal Biol 79:376-383

Daan S, Aschoff J (1982) Circadian contributions to survival. In: Aschoff J, Daan S, Groos GA (eds) Vertebrate circadian systems. Springer-Verlag Editions, Berlin, pp 305-321

Daly M, Behrends PR, Wilson MI, Jacobs LF (1992) Behavioural modulation of predation risk: moonlight avoidance and crepuscular compensation in a nocturnal desert rodent, Dipodomys merriami. Anim Behav 44:1-9

Elangovan V, Marimuthu G (2001) Effect of moonlight on the foraging behaviour of a megachiropteran bat Cynopterus sphinx. J Zool 253:347-350

ENETWILD Consortium, Acevedo P, Croft S, Smith G, Blanco-Aguiar J, Fernández-López J, Scandura M, Apollonio M, Ferroglio E, Keuling O, Sange M, Zanet S, Brivio F, Podgòrski T, Petrovic K,
Soriguer R, Vicente J (2020) Validation and inference of highresolution information (downscaling) of ENETwild abundance model for wild boar. EFSA Support Publ 1:17

Fanelli A, Perrone A, Ferroglio E (2021) Spatial and temporal dynamics of wild boars Sus scrofa hunted in Alpine environment. Eur J Wildl Res 67:47

Fattorini N, Pokheral CP (2012) Activity and habitat selection of the Indian crested porcupine. Ethol Ecol Evol 24:377-387

Ferrari MC, Sih A, Chivers DP (2009) The paradox of risk allocation: a review and prospectus. Anim Behav 78:579-585

Ficetola GF, Bonardi A, Mairota P, Leronni V, Padoa-Schioppa E (2014) Predicting wild boar damages to croplands in a mosaic of agricultural and natural areas. Curr Zool 60:170-179

Fitak R (2020) Package "CircMLE”. Maximum Likelihood Anaylsis of Circular Data. Available at https://cran.r-project.org/web/ packages/CircMLE/CircMLE.pdf. Accessed on 16.02.2021

Greco I, Fedele E, Salvatori M, Rustichelli MG, Mercuri F, Santini G, Rovero F, Lazzaro L, Foggi B, Massolo A, De Pietro F, Zaccaroni M (2021) Guest or pest? Spatio-temporal occurrence and effects on soil and vegetation of the wild boar on Elba island. Mammal Biol 101:193-206

Griffin PC, Griffin SC, Waroquiers C, Mills LS (2005) Mortality by moonlight: predation risk and the snowshoe hare. Behav Ecol 16:938-944

Grignolio S, Brivio F, Apollonio M, Frigato E, Tettamanti F, Filli $\mathrm{F}$, Bertolucci C (2018) Is nocturnal activity compensatory in chamois? A study of activity in a cathemeral ungulate. Mammal Biol 93:173-181

Harmsen BJ, Foster RJ, Silver SC, Ostro LE, Doncaster CP (2011) Jaguar and puma activity patterns in relation to their main prey. Mammal Biol 76:320-324

Hernández M, Jara-Stapfer DM, Muñoz A, Bonacic C, Barja I, Rubio AV (2021) Behavioral responses of wild rodents to owl calls in an Austral temperate forest. Animals 11:428

Hughes-Brandl M (2018) Package 'NightDay'. Night and day boundary plot function. Available at: https://cran.r-project.org/web/ packages/NightDay/NightDay.pdf. Accessed on 06.09.2021

Jasińska KD, Jackowiak M, Gryz J, Bijak S, Szyc K, Krauze-Gryz D (2021) Occurrence and activity of roe deer in urban forests of Warsaw. Environm Sci Proc 3:35

Jetz W, Steffen J, Linsenmair KE (2003) Effects of light and prey availability on nocturnal, lunar and seasonal activity of tropical nightjars. Oikos 103:627-639

Johann F, Handschuh M, Linderoth P, Heurich M, Dormann CF, Arnold J (2020) Variability of daily space use in wild boar Sus scrofa. Wildl Biol. https://doi.org/10.2981/wlb.00609

Joubert FC, Eloff FC (1971) Notes on the ecology and behaviour of the black rhinoceros Diceros bicornis Linn. 1758 in South West Africa. Modoqua 1:5-53

Keuling O, Stier N, Roth M (2008) How does hunting influence activity and spatial usage in wild boar Sus scrofa L. Eur J Wildl Res 54:729-737

Keuling O, Baubet E, Duscher A, Ebert C, Fischer C, Monaco A, Podgorski T, Prevot C, Ronnenberg K, Sodeikat G, Stier N, Thurfjell H (2013) Mortality rates of wild boar Sus scrofa L. in central Europe. Eur J Wildl Res 59:805-814

Kie JG (1999) Optimal foraging and risk of predation: effects on behavior and social structure in ungulates. J Mammal 80:1114-1129

Kronfeld-Schor N, Dominoni D, De la Iglesia H, Levy O, Herzog ED, Dayan T, Helfrich-Forster C (2013) Chronobiology by moonlight. Proc R Soc B Biol Sci 280:20123088

Landler L, Ruxton GD, Malkemper EP (2019) The Hermans-Rasson test as a powerful alternative to the Rayleigh test for circular statistics in biology. BMC Ecol 19:1-8 
Lashley MA, Chitwood MC, Biggerstaff MT, Morina DL, Moorman CE, DePerno CS (2014) White-tailed deer vigilance: the influence of social and environmental factors. PLoS One 9:e90652

Laurenzi A, Bodino N, Mori E (2016) Much ado about nothing: assessing the impact of a problematic rodent on agriculture and native trees. Mammal Res 61:65-72

Lemel J, Truvé J, Söderberg B (2003) Variation in ranging and activity behaviour of European wild boar Sus scrofa in Sweden. Wildl Biol 9:29-36

Lima SL, Dill LM (1990) Behavioral decisions made under the risk of predation: a review and prospectus. Canad J Zool 68:619-640

Lima Sábato MA, de Melo LFB, Magni EMV, Young RJ, Coelho CM (2006) A note on the effect of the full moon on the activity of wild maned wolves, Chrysocyon brachyurus. Behav Processes 73:228-230

Link A, Di Fiore A, Galvis N, Fleming E (2012) Patterns of mineral lick visitation by lowland tapir (Tapirus terrestris) and lowland paca (Cuniculus paca) in a western Amazonian rainforest in Ecuador. Mastozool Neotr 19:63-70

Lizcano DJ, Cavelier J (2000) Daily and seasonal activity of the mountain tapir (Tapirus pinchaque) in the Central Andes of Colombia. J Zool 252:429-435

Luzi G, Mori E, Puddu G, Zapparoli M (2021) Does the crested porcupine select coppice forest? Habitat preference and activity patterns of a large rodent in the Lago di Vico Natural Reserve. Mammalia. https://doi.org/10.1515/mammalia-2020-0143

Massei G, Genov PV, Staines BW, Gorman ML (1997) Factors influencing home range and activity of wild boar (Sus scrofa) in a Mediterranean coastal area. J Zool 242:411-423

Massei G, Kindberg J, Licoppe A, Gačić D, Šprem N, Kamler J, Baubet E, Hohmann U, Monaco A, Ozolins J, Cellina S, Podgòrski T, Fonseca C, Markov N, Pokorny B, Rosell C, Náhlik A (2015) Wild boar populations up, numbers of hunters down? A review of trends and implications for Europe. Pest Manage Sci 71:492-500

Medici EP (2010) Assessing the viability of lowland tapir populations in a fragmented landscape. Ph.D. Dissertation, University of Kent Canterbury, UK

Meredith M, Ridout M (2014) Overview of the Overlap Package. Available from: http://cran.cs.wwu.edu/web/packages/overlap/vigne ttes/overlap.pdf. Accessed on 12.02.2021

Monterroso P, Alves PC, Ferreras P (2013) Catch me if you can: diel activity patterns of mammalian prey and predators. Ethol 119:1044-1056

Morelle K, Podgórski T, Prévot C, Keuling O, Lehaire F, Lejeune P (2015) Towards understanding wild boar Sus scrofa movement: a synthetic movement ecology approach. Mammal Rev 45:15-29

Mori E, Nourisson DH, Lovari S, Romeo G, Sforzi A (2014) Selfdefence may not be enough: moonlight avoidance in a large, spiny rodent. J Zool 294:31-40

Mori E, Bagnato S, Serroni P, Sangiuliano A, Rotondaro F, Marchianò V, Cascini V, Poerio L, Ferretti F (2020) Spatiotemporal mechanisms of coexistence in an European mammal community in a protected area of southern Italy. J Zool 310:232-245

Mori E, Cicero M, Lovari S, Zaccaroni M, Salomoni S, Vendramin A, Augugliaro C (2021a) Occupancy and activity rhythms of the Siberian roe deer. Biologia. https://doi.org/10.1007/ s11756-021-00790-1

Mori E, Lazzeri L, Ferretti F, Gordigiani L, Rubolini D (2021b) The wild boar Sus scrofa as a threat to ground-nesting species: an artificial nest experiment. J Zool. https://doi.org/10.1111/jzo.12887

Ohashi H, Saito M, Horie R, Tsunoda H, Noba H, Ishii H, Kuwabara T, Hiroshighe Y, Koike S, Hoshino Y, Toda Y, Kaji K (2013) Differences in the activity pattern of the wild boar Sus scrofa related to human disturbance. Eur J Wildl Res 59:167-177
Oliveira-Santos LGR, Machado-Filho LCP, Tortato MA, Brusius L (2010) Influence of extrinsic variables on activity and habitat selection of lowland tapirs (Tapirus terrestris) in the coastal sand plain shrub, southern Brazil. Mammal Biol 75:219-226

Ollivier FJ, Samuelson DA, Brooks DE, Lewis PA, Kallberg ME, Komáromy AM (2004) Comparative morphology of the tapetum lucidum (among selected species). Vet Ophtalm 7:11-22

Pagon N, Grignolio S, Pipia A, Bongi P, Bertolucci C, Apollonio M (2013) Seasonal variation of activity patterns in roe deer in a temperate forested area. Chronobiol Intern 30:772-785

Penteriani V, Kuparinen A, del Mar DM, Palomares F, López-Bao JV, Fedriani JM, Calzada J, Moreno S, Villafuerte R, Campioni L, Lourenço R (2013) Responses of a top and a meso predator and their prey to moon phases. Oecol 173:753-766

Podgórski T, Baś G, Jędrzejewska B, Sönnichsen L, Śnieżko S, Jędrzejewski W, Okarma H (2013) Spatiotemporal behavioral plasticity of wild boar (Sus scrofa) under contrasting conditions of human pressure: primeval forest and metropolitan area. J Mammal 94:109-119

Prugh LR, Golden CD (2014) Does moonlight increase predation risk? Meta-analysis reveals divergent responses of nocturnal mammals to lunar cycles. J Anim Ecol 83:504-514

R Core Team (2013) R: A language and environment for statistical computing. Vienna, Austria: R Foundation for Statistical Computing ISBN 3-900051-07-0. http://www.Rproject.org/ Accessed on 22.01 .2021

Refinetti P (2016) Circadian physiology, 3rd edn. CRC Press, Boca Raton

Rossa M, Lovari S, Ferretti F (2021) Spatiotemporal patterns of wolf, mesocarnivores and prey in a Mediterranean area. Behav Ecol Sociobiol 75:1-13

Rowcliffe JM, Field J, Turvey ST, Carbone C (2008) Estimating animal density using camera traps without the need for individual recognition. J Appl Ecol 45:1228

Rowcliffe JM, Kays R, Kranstauber B, Carbone C, Jansen PA (2014) Quantifying levels of animal activity using camera trap data. Methods Ecol Evol 5:1170

Russo L, Massei G, Genov PV (1997) Daily home range and activity of wild boar in a Mediterranean area free from hunting. Ethol Ecol Evol 9:287-294

Santilli F, Varuzza P (2013) Factors affecting wild boar (Sus scrofa) abundance in Southern Tuscany. Hystrix 24:169-173

Schlageter A, Haag-Wackernagel D (2012) Evaluation of an odor repellent for protecting crops from wild boar damage. J Pest Sci $85: 209-215$

Shortridge GC (1934) The Mammals of South-West Africa. Heinemann, London

Stillfried M, Fickel J, Börner K, Wittstatt U, Heddergott M, Ortmann S, Kramer-Schadt S, Frantz AC (2017) Do cities represent sources, sinks or isolated islands for urban wild boar population structure? J Appl Ecol 54:272-281

Sutherland DR, Predavec M (1999) The effects of moonlight on microhabitat use by Antechinus agilis (Marsupialia: Dasyuridae). Austr J Zool 47:1-17

Symonds ME, Moussalli A (2011) A brief guide to model selection, multimodel inference and model averaging in behavioural ecology using Akaike's information criterion. Behav Ecol Sociobiol 65:13-21

Theuerkauf J, Jędrzejewski W, Schmidt K, Okarma H, Ruczyński I, Śniezko S, Gula R (2003) Daily patterns and duration of wolf activity in the Białowieza Forest, Poland. J Mammal 84:243-253

Visscher DR, Macleod I, Vujnovic K, Vujnovic D, Dewitt PD (2017) Human risk induced behavioral shifts in refuge use by elk in an agricultural matrix. Wildl Soc Bull 41:162-169 
Viviano A, Amori G, Luiselli L, Oebel H, Bahleman F, Mori E (2020) Blessing the rains down in Africa: spatiotemporal behaviour of the crested porcupine Hystrix cristata (Mammalia: Rodentia) in the rainy and dry seasons, in the African savannah. Tropical Zool 33:113-124

Viviano A, Mori E, Fattorini N, Mazza G, Lazzeri L, Panichi A, Strianese L, Mohamed WF (2021) Spatiotemporal overlap between the European brown hare and its potential predators and competitors. Animals 11:562

Walther FR (1973) Round-the-clock activity of Thomson's gazelle (Gazella thomsoni Gunther 1884) in the Serengeti National Park. Zeitschr Tierpsychol 32:75-105

Webb SL, Gee KL, Strickland BK, Demarais S, DeYoung RW (2010) Measuring fine-scale white-tailed deer movements and environmental influences using GPS collars. Intern J Ecol 2010:459610

Wood SN (2017) Generalized Additive Models: An Introduction with $\mathrm{R}$, 2nd edn. Chapman and Hall/CRC, London

Wood SN (2013) A simple test for random effects in regression models. Biometrika 1, ast038
Woodside GJ (2010) Rocky mountain elk (Cervus elaphus nelsonii) behavior and movement in relation to lunar phases. MSc Thesis in Rangeland Ecology and Management, Oregon State University, Corvallis, Oregon, USA

Wronski T, Apio A, Plath M (2006) Activity patterns of bushbuck (Tragelaphus scriptus) in Queen Elizabeth National Park. Behav Processes 73:333-341

Youthed GJ, Moran VC (1969) The lunar-day activity rhythm of myrmeleontid larvae. J Ins Physiol 15:1259-1271

Zanni M, Brivio F, Grignolio S, Apollonio M (2021) Estimation of spatial and temporal overlap in three ungulate species in a Mediterranean environment. Mammal Res 66:149-162

Zozzoli R, Menchetti M, Mori E (2018) Spatial behaviour of an overlooked alien squirrel: the case of Siberian chipmunks Eutamias sibiricus. Behav Processes 153:107-111

Publisher's note Springer Nature remains neutral with regard to jurisdictional claims in published maps and institutional affiliations. 